\title{
Microprocessor Based Controller For A Motor Car Park
}

\author{
${ }^{1}$ Ebegba, D and ${ }^{2}$ Anyasi, F.I, \\ ${ }^{1}$ Department of Electrical and Electronics Engineering, Petroleum Training Institute, P.M.B, 20, Effurun, Delta \\ State, Nigeria. \\ ${ }^{2}$ Department of Electrical and Electronics Engineering, Ambrose Alli University, P.M.B 14, Ekpoma. Edo State,
} Nigeria

\begin{abstract}
This work involves the implementation of a microprocessor based motor car park management system. Embedded system design approach was adopted. Components were selected and interconnected according to their function. The system comprised of two parts, a small hardware part and a program code or software part. The hardware part has a micro controller, which is a mini-computer. The microprocessor was programmed to perform the counting task. The system records the vehicles inside the parking lot and notifies the available space, thereby controlling the access into the parking lot.
\end{abstract}

\section{Introduction}

One common feature of public buildings and edifices such as church, office complex, school campus, supermarket, stadium, company yards, eateries, cinema, etc, is an open space where vehicles are parked. [1]. This has become the norm these days when the ownership and use of vehicles are on the increase. This space usually reserved for parking vehicle are called parking lot. [2]. The parking lots as seen in the above mentioned places are of different orientation. Some are just open field nearby the building, others are specially marked out and tiled. Furthermore, some are properly floored with concrete or interlocking tiles, and the position for each vehicle to park is marked out with white paints. Also the entire perimeter of the parking lot is fenced. Two gates are mounted representing entry and exit for the vehicles coming in and going out. With this arrangement, the owners of the parking lot are able to achieve orderliness, security of the vehicles using the parking lot and control of movement within the parking lot vicinity.

More so, access into the parking lot can be controlled. In this situation or scenario described above, all activities of manning and managing the parking lot is done manually. Personnel called ushers or traffic warders are saddled with the responsibility of managing the parking lot, [3].

However, with the advancement in the field of electronic and control engineering, the trend has been towards automation of our every day to day activity. This removes stress and fatigue in realizing our every day task. Manually operated systems are prone to errors and sad stories due to carelessness of the duty personnel. To remove this malady and ensure efficiency, the design idea of the automatic parking lot was conceived. The automatic car parking lot control system is an example of daily application of control and electronic engineering. The system manages a car parking lot with little or no human supervision and interference. Still on the scenario discussed above, any vehicle that goes through the entry gate (which is open or switch on) is counted and displayed. Also any vehicle that goes out from the parking lot through the exit gate is counted and displayed. The system has a preprogrammed reckoning pattern. When a vehicle goes through the entry gate, the counter increments by one, and when a vehicle goes out through the exit, the counter decrement the already countered value by one. In addition when the parking space is filled the system will automatically close the entrance gate turn on a red light to announce this, [4].

\section{Generation of infrared beam}

Infrared beam are electromagnetic with wavelength than those of visible light, extending from the nominal red edge of the visible spectrum at 0.74 micrometers $(\mu \mathrm{m})$ to $300 \mathrm{Nm}$. This range of wavelengths corresponds to a frequency range of approximately 1 to $400 \mathrm{~Hz}$ and photon energy $1.24 \mathrm{MeV}-1.7 \mathrm{eV}$, [5]. Basically, infrared emitter diodes were used as source of infrared.

They are basically light emitting diodes whose semiconductor material are Gallium Arsenide (GaAs) and Aluminum gallium Arsenide (A2GaAs). When forward biased, electrons are able to recombine with holes within the device, releasing energy in the form of photons. This effect is called electroluminescence. Using the mentioned semiconductor for its fabrication gives the photon energy in the infrared region, thus resulting in an infrared diode 


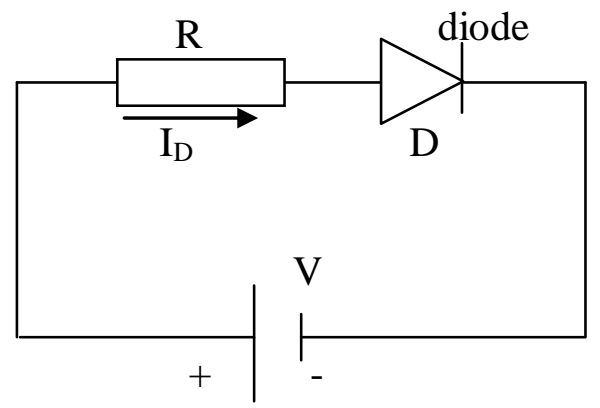

Fig 1 A forward biased diode

Just like every other light emitting diode, the use of a current limiting resistor is very important. It prevent damage due to excessive current flow from Fig 1. Using Kirchoff's voltage law

$$
\begin{aligned}
& V-i d R-V_{0}=0 \\
& V=V_{D}-i_{D} R
\end{aligned}
$$

$\mathrm{V}_{\mathrm{D}}$ represents the junction potential drop of the infrared diode. This value is given by the manufacturer in the data sheet. While $\mathrm{V}=$ supply voltage and $\mathrm{i}_{\mathrm{D}}$ as the operating current of the diode. From equation (2),

$$
R=\frac{V-V_{D}}{i_{D}}
$$

\section{The carrier circuit}

Basic frequency generating circuits can be used. However, for reasons of low component count, the single chip astable multivibrator integrated circuits was used the single chip frequency generator circuit is given in Figure 2

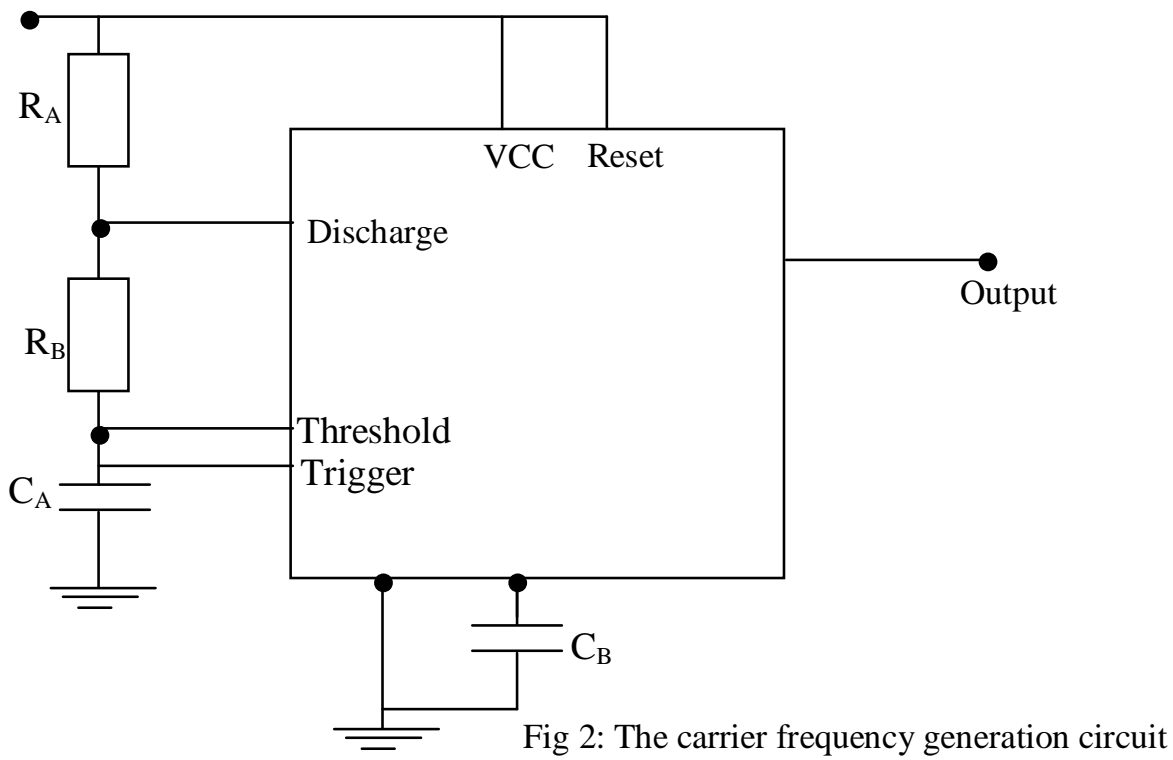

The carrier frequency generation circuit is built from a single timer chip, the popular 555 timer IC. The frequency generator circuit's frequency is determined by $R_{A}$, and $R_{B}$, while $C_{A}$ and $C_{B}$ are meant to prevent false oscillation. The output for astable connection, changes continuously between high and low at a time determined by the RC network.

Thus time of $\mathrm{HIGH}\left(\mathrm{T}_{\mathrm{H}}\right)=0.69\left(\mathrm{R}_{\mathrm{A}}+2 \mathrm{R}_{\mathrm{B}}\right) \mathrm{CA}$

And Time of Low $\left(\mathrm{T}_{\mathrm{L}}\right)=0.69 \mathrm{C}_{\mathrm{A}}\left(\mathrm{R}_{\mathrm{B}}\right)$

$\therefore$ Total Time between HIGH and LOW transistor

$$
T=T_{H}+T_{L}
$$

But period $\mathrm{T}=$ time for a complete circle

Thus, Peroid $=T_{H}+T_{L}=T$ 


$$
\begin{aligned}
& T=0.69 C_{A}\left(R_{A}+R_{B)}+0.69 C_{A} R_{B}\right. \\
& T=0.69 C_{A}\left(R_{A}+R_{B)}+R_{B}\right) \\
& T=0.69 C_{A}\left(R_{A}+2 R_{B}\right)
\end{aligned}
$$

Furthermore,

$$
\begin{aligned}
& \text { frequency, } F=\frac{1}{\text { period }} \\
& F=\frac{1}{T} \\
& f=\frac{1}{0.69 C_{A}\left(R_{A}+2 R_{B}\right)} \\
& 1.44=\frac{1}{C_{A}\left(R_{A}+2 R_{B}\right)} \\
& f=\frac{1.44}{C_{A}\left(R_{A}+2 R_{B}\right)}
\end{aligned}
$$

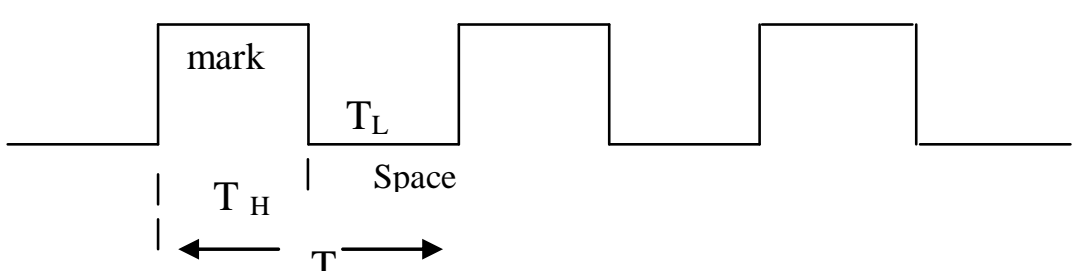

Fig 3: Output wave form

$$
\begin{aligned}
& \text { Duty cycle }=\frac{\text { mark }}{\text { Space }}=\frac{T_{L}}{T_{H}+T_{L}} \\
& =\frac{0.69 C_{A} R_{B}}{0.69 C_{A}\left(R_{A}+2 R_{B}\right)} \\
& =\frac{R_{B}}{R_{A}+2 R_{B}}
\end{aligned}
$$

\section{INFRARED DETECTION}

Several arrangements are adopted in detecting the infrared beam first the transmitted infrared beam is first detected, and then demodulated to release the IC beam. This practice prevents interference from ambient light. The infrared module is adopted for this work. The IR module works on pulse code modulation. The detector circuit adopted is given in Fig 4 .

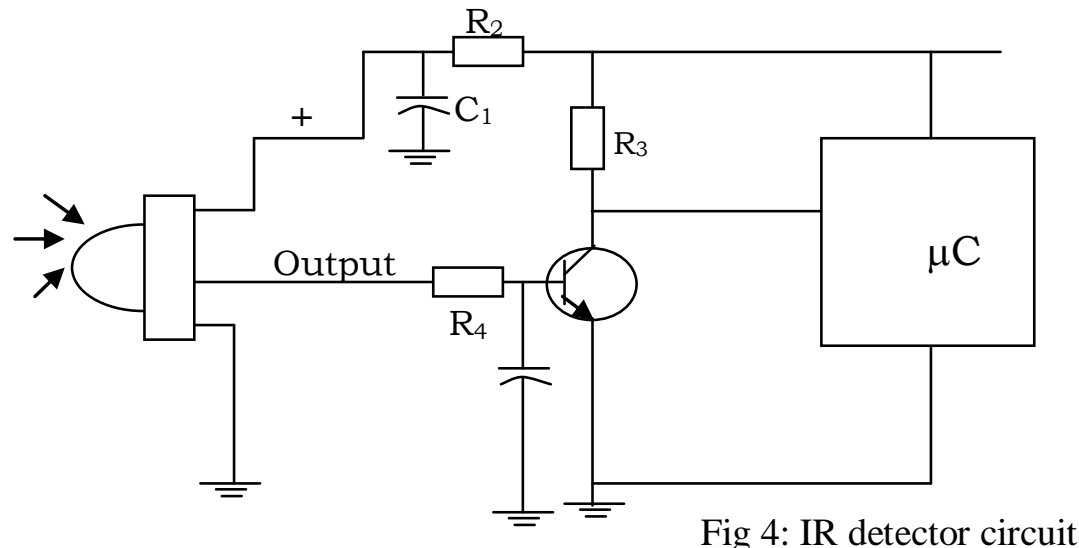


The data signal received by the IR module must fulfill the following conditions.

- Carrier frequency should be close to center frequency of the band pass (e.g $38 \mathrm{KHz})$.

- Burst length should be 10 cycles/burst or longer

Some disturbance signals which are suppressed are

- DC light (e.g from tungsten bulb or sunlight

- Continuous signal at $38 \mathrm{KHz}$ or at any other frequency

- Signals from fluorescent lamps with electronic ballast.

From Fig 4, Resistor $R_{2}$ limits current to the IR module, $C_{1}$ filters offer power line disturbance. $R_{3}$ is an output/load resistor to produce voltage at microcontroller input port.

$\mathrm{R}_{4}$ is a fixed base biasing resistor for transistor $\mathrm{Q}$ which act as a switch for switching operation, the transistor analysis is given as

$$
\begin{aligned}
\mathrm{IC} & =\text { current through } \mathrm{R}_{3} \\
i_{c} & =\frac{V}{R}
\end{aligned}
$$

However, in practice logic zero at not $0 \mathrm{~V}$ but $0.05 \mathrm{~V}$

$$
\therefore i_{c}=\frac{V-0.05}{R}
$$

Furthermore,

$$
i_{B}=\frac{i_{C}}{\beta}
$$

Where $\mathrm{i}_{\mathrm{B}}=$ base current

$\mathrm{i}_{\mathrm{C}}=$ collector current

$\beta=$ transistor forward gain

$\therefore$ Equation (9) becomes

$$
\mathrm{i}_{\mathrm{B}}=\frac{V-0.05}{\frac{R}{\beta}}=\frac{V-0.05}{\beta R}
$$

but, $\mathrm{V}_{\text {out }}-\mathrm{L}_{\mathrm{B}} \mathrm{R}_{4}-\mathrm{V}_{\mathrm{BE}}=0$

$\mathrm{V}_{\mathrm{DE}}=$ transistor base emitter voltage

$$
\begin{aligned}
& \mathrm{V}_{\text {out }}=\text { output of IF module } \\
& \mathrm{V}_{\text {out }}-\left[\frac{V-0.05}{\beta R}\right] R_{4}-V_{B E}=0 \\
& \mathrm{~V}_{\text {out }}-\mathrm{R}_{4}(\mathrm{~V}-0.05)
\end{aligned}
$$

\section{The Microcontroller}

The microcontroller has large capacity for data processing; however it needs to synchronize all internal stage and operation. Thus, to achieve this, it has to run at a high clock frequency. The clock frequency determines its speed. Also, the speed determines how many instructions that can be executed per seconds.

The microcontroller has an internal oscillator controlled by the external crystal connected. The crystal Tx frequency determines the frequency of operation of the microcontroller the capacitors $\mathrm{C}_{3}$ and $\mathrm{C}_{4}$ aids the crystal oscillator they enables to crystal to resonate, see Figure 5.

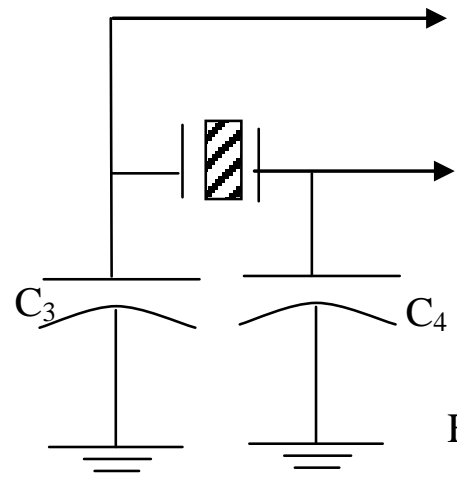

Fig 5: Resonator circuit 
Thus, the use of a single resonator of frequency equal to the crystal oscillator can replace the circuit of Fig 5, values of $\mathrm{C}_{3}, \mathrm{C}_{4}$ and $\mathrm{TX}_{1}$ are specified by manufacturer.

Resettling the microcontroller is done in two ways, either by hardware or software. The hardware reset circuit is adopted and shown in Fig 6.

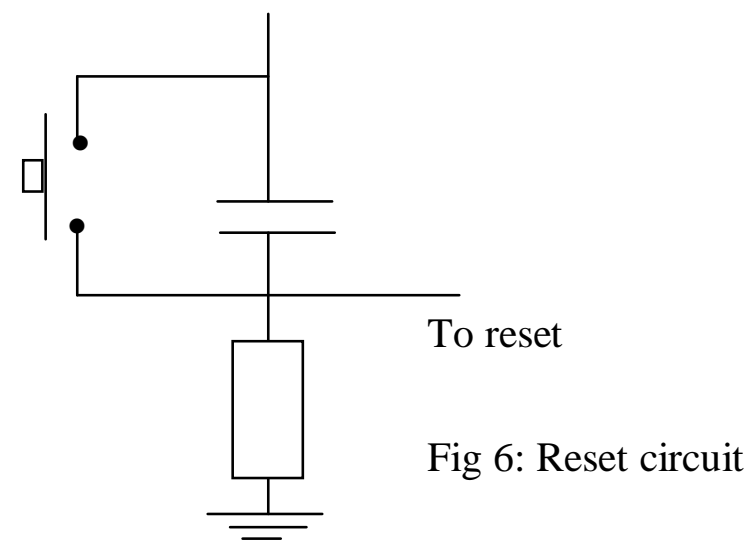

It basically consists of an RC circuit to produce time delay. If the reset input is held for time $\mathrm{t}$ greater than $1 \mathrm{~ms}$ the microcontroller recourses to start of program memory location.

For an RC network as Fig 6,

Time constant $\mathrm{T}=\mathrm{RC}$

$$
\mathrm{R}=\mathrm{T} / \mathrm{C}
$$

\section{Output Devices}

The LCD is an output device to display the vehicle count. A $16 \times 2$ LCD was used to enable but numerical value and message being display at the same time

$\therefore$ Transistor collector current $\mathrm{I}_{\mathrm{C}}$ will be equal to $\mathrm{i}_{\mathrm{c}}$

Furthermore, the transistor should be able to handle this current.

Transistor base current;

$$
i_{b}=\frac{I_{C}}{\beta}=\frac{i_{c}}{\beta}
$$

Calculating the value of $\mathrm{R}_{6}$ and $\mathrm{R}_{7}$ will be done using the expression;

$$
\begin{aligned}
& V_{\text {out }}-V_{B E}-i_{b} R_{b}=0 \\
& V_{\text {out }} R_{b}=\frac{V_{\text {out }}-V_{B E}}{i_{b}}
\end{aligned}
$$

$\mathrm{R}_{\mathrm{b}}$ stand for $\mathrm{R}_{6}$ and $\mathrm{R}_{7}$ for transistor $\mathrm{Q}_{2}$ and $\mathrm{Q}_{3}$ respectively

\section{The Relay Drivers}

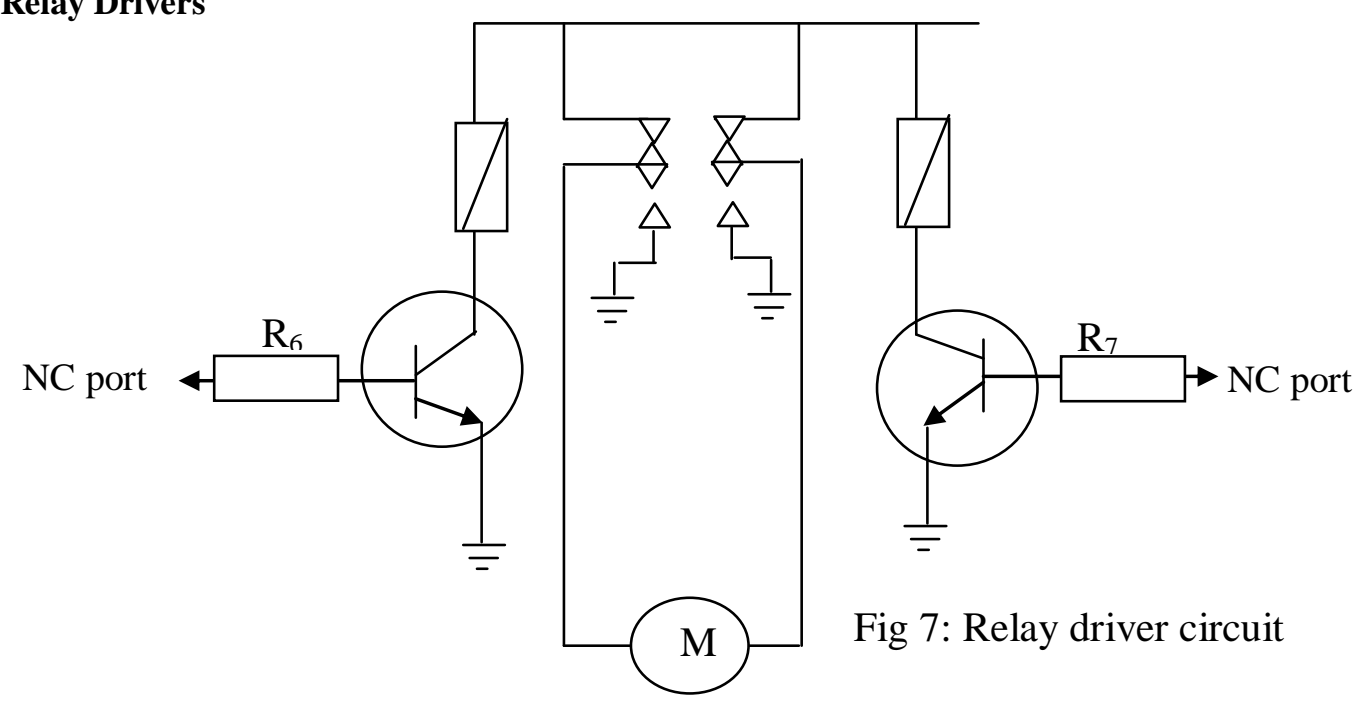


The relay driver circuit consist of two transistors two relays as shown in Fig 7. The relay forms an interface for driving the mechanism for closing and opening the gate. The choice of the relay depends on the power rating of the driving motor of the relay.

relay coil current $=\underline{\text { relay coil voltage }}$

\section{Software Design}

$$
\text { relay coil resistance }
$$

The software consists of the program or instruction code upon which microcontroller will run. The software program determines the operation of the system in general. First approach in the development of the program code, involves generating of the program algorithm.

\section{Program Algorithm}

Algorithm is a set of rules or processes (procedures) for solving a problem in a finite number of steps, [7].

Algorithm is implemented with instruction code either in high level language are program step are: [8]

i. set vectors

ii. check count for maximum value

iii. close gate if count is maximum and display full

iv. if not increment count on entry and decrement count on exist

Flow Chart

v. repeat until count is maximum

Further development includes producing a flow chart. A flow chart is a diagrammatic representation of the program steps. The work flow chart is given in Fig 8.

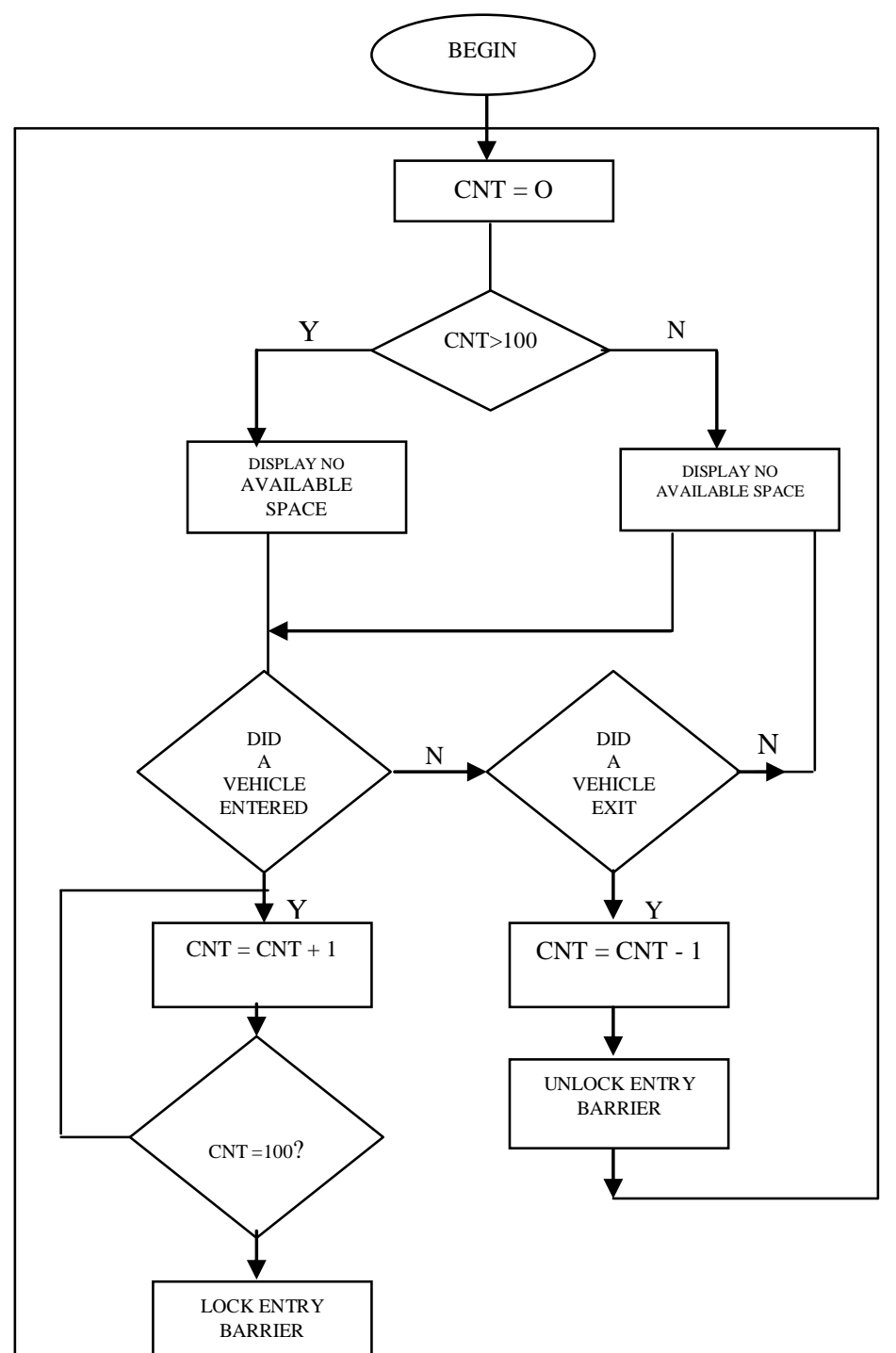

Fig 8: Flow chart 


\section{Conclusion}

This system aims and objectives as stated in the problem statement have been achieved. The completed work had been tested and worked as required.

A research approach was adopted in the implementation of this system, the commercial related product were studied, from whence a workable circuit was design. The design was done using embedded system technology. This is to reduce component count, makes the system simple and cost effective.

In the realization, of the unit, certain challenges were faced, such as component procurement, hardware and software implementation. These were overcome with appropriate consultations and research.

Furthermore, the work has enabled me to apply engineering knowledge in solving everyday problem.

\section{Recommendation}

The automatic parking lot control system is an embedded based system. Thus, its capability can be extended by modification of the program code using the appropriate code and interface circuit; the system can be interface to a PC (personal computer). Furthermore, the vehicle sensor can be change without a change in the adjoining circuitry. Also, the gate mechanism can be of any type, bar, slide elbow etc

\section{References}

[1] Richard S. Beebe (2001): Automated parking status in the United States - Advantages and Criteria. Parking and transportation planning consulting engineers Group Inc. USA

[2] MacCarley, C.A., S. Hockaday, D. Need, S. Taff, (1992): Evaluation of Video Image Processing Systems for Traffic Detection, Transportation Research Record No. 1360, National Research Council, Washington D.C..

[3] Hockaday, S., (1991): Evaluation of Image Processing Technology for Applications in Highway Operations Final Report, TR 91-2, Transportation Res. Group, California Polytechnical State University, San Luis Obispo, California, JAMAR Technologies, Inc., Catalog Number 7, Horsham, PA.

[4] http://technologyinterface.nmsu.edu/fal.09.

[5] http://www.ctre.iastate.edu/research/wim_pdf/index.htm

[6] Dogan Ibrahim (2006); 30 Project using Pic Basic and Pic Basic PRO Elsevier Book Company San Diego $1^{\text {st }}$ Edition.

[7] Fowler, D. W., (1996): Selection of Bonding Materials for Piezoelectric Sensors, Proceedings - National Traffic Data Acquisition Conference, Vol. II, NM-NATDAC96, Albuquerque, NM, State Highway and Transportation Dept., Santa Fe, NM.

[8] Kenneth, Ayala (1991); The 8051 Microcontroller, Architecture, programming and applications, West Publishing Company, New York. $2^{\text {nd }}$ Edition.

[9] Apogee/Hagler Bailly, (1998): Intelligent Transportation Systems: Real World Benefits, FHWA-JPO-98- 018.

[10] ASTM E1318-94, (1994): Standard Specification for Highway Weigh-in-Motion (WIM) with User Requirements and Test Method, Annual Book of ASTM Standards, vol. 04.03, West Conshohocken, PA,

[11] Caldera, R., (1996): Long-Term Stable Quartz WIM Sensors, Proceedings - National Traffic Data Acquisition Conference, Vol. II, NM-NATDAC96, Albuquerque, NM State Highway and Transportation Dept., Santa Fe, NM.

[12] Castle Rock Consultants, (1988): Automated Traffic/Truck Weight Monitoring Equipment (Weigh-in-Motion), FHWA-DP-88-76006. 